\title{
A method for cone-beam computed tomography volumetric evaluation of lyophilized bovine bone block for alveolar ridge augmentation: a retrospective study
}

\author{
Otacílio Luiz Chagas Júnior ${ }^{1}$, Paulo Eduardo Kreisner ${ }^{2}$, Pedro Henrique de Azambuja Carvalho ${ }^{3}$ \\ ${ }^{1}$ Graduate Program in Dentistry, Oral and Maxillofacial Surgery, School of Dentistry at Federal University of Pelotas, RS, Brazil; ${ }^{2}$ MERCOSUL \\ Education and Research Institute in Dentistry, Porto Alegre, Brazil; ${ }^{3}$ Collaborating Researcher and Professor, Graduate Program in Dentistry, Oral \\ and Maxillofacial Surgery, School of Dentistry at Federal University of Pelotas, RS, Brazil \\ Contributions: (I) Conception and design: OL Chagas Júnior, PH de Azambuja Carvalho; (II) Administrative support: PE Kreisner; (III) Provision of \\ study materials or patients: PE Kreisner; (IV) Collection and assembly of data: OL Chagas Júnior, PE Kreisner; (V) Data analysis and interpretation: \\ OL Chagas Júnior, PH de Azambuja Carvalho; (VI) Manuscript writing: All authors; (VII) Final approval of manuscript: All authors. \\ Correspondence to: Otacílio Luiz Chagas Júnior, DDS, MSc, PhD. Graduate Program in Dentistry, School of Dentistry, Federal University of Pelotas, \\ Rua Gonçalves Chaves, 457 - 3º Andar, Pelotas-RS 96015-560, Brazil. Email: otaciliochagasjr@gmail.com.
}

\begin{abstract}
Background: In the present days there are a myriad of bone substitutes available to maxillary reconstruction. Among them, bovine xenograft particulate is a well-known bone substitute and widely used in implantology, such filling the fresh extracted sockets or as filler for sinus floor elevation. However, few studies have been reported the use of a block from that origin to horizontal alveolar ridge augmentation previous dental implants installation. The aim of this study was to assess the mineralized tissue volume after horizontal ridge augmentation with lyophilized bovine bone block.

Methods: This cross-sectional observational study was conducted according to STROBE statement. Files from adult patients who underwent maxillary augmentation procedures previous to implant placement, between 2010 and 2016, were screened following inclusion criteria. Cone beam computed tomographies were taken previously to the reconstruction and at least after 8 months later, previously to dental implants surgery.

Results: Eleven grafted areas were evaluated in a sample of 9 postoperative tomography by the OSIRIX lite v 8.0.2 software, using "pencil" tools for manual selection of the grafted area, slice by slice, and then "volume ROI" and "calculate volume" program tools. The results obtained showed a volumetric gain of $283.9 \mathrm{~mm}^{3}$.

Conclusions: Thus, it was possible to conclude that lyophilized bovine bone block provides enough volume gain in horizontal ridge augmentation techniques.
\end{abstract}

Keywords: Bone graft; Xenografts; bone transplantation; heterologous graft

Received: 01 April 2021; Accepted: 06 December 2021; Published: 10 March 2022.

doi: $10.21037 /$ fomm-21-44

View this article at: https://dx.doi.org/10.21037/fomm-21-44

\section{Introduction}

One of the most important aims in modern dentistry is to reestablish patients' function, aesthetics, and quality of life, regardless of previous illnesses or disability in the stomatognathic system $(1,2)$.

Since the development of dental implants, oral rehabilitation is at forefront of the need for bone with sufficient quantity and quality to support the functional loads and aesthetic needs in implant-supported dentures; therefore, the concept of a tridimensional position of implants resembling the original teeth position was proposed (2-5).

However, local conditions in alveolar ridges, such as severe atrophy, periodontal disease, or traumatic injuries, often lead to insufficient alveolar bone volume, in the horizontal, 
vertical, or both directions, due to centripetal alveolar bone resorption, which impaired implant placement in the most favorable position for biomechanics and aesthetics $(2,6)$. For this reason, bone grafting techniques have been used previously or concomitant to implant placement to promote correct orientation and predictability (7).

Autogenous bone is considered the gold standard for bone grafting procedures owing to its osteoconductivity, osteoinduction, and osteogenesis properties $(8,9)$. However, the need for a second surgery site, increase in surgery time, and possible postoperative morbidity are considered disadvantages of this technique $(6,10)$.

The xenogeneic bone of bovine origin is currently indicated in cases where the autogenous bone is not a viable alternative because of the patients' condition or there is a limited amount of bone (10). In addition, the bovine bone presents good biocompatibility $(11,12)$ and has different presentation forms such as a particulate or block with high success rates $(13,14)$. Furthermore, regarding long-term stability and resorption, deproteinized bovine bone was proposed to lower resorption rates than did autologous bone (15), with a similar implant survival rate (8).

In the current literature, few studies have investigated the use of lyophilized bovine bone matrix in block (LBBM) to alveolar ridge reconstruction (11,16-25). Conversely, sufficient data are available regarding the same material in granule form, in particular to post-extraction socket preservation and maxillary sinus lifting. Thus, this study aimed to assess the bone volume gain obtained after horizontal ridge augmentation using LBBM in pre-implant surgeries. This article was prepared following the STROBE reporting checklist (available at https://fomm.amegroups. com/article/view/10.21037/fomm-21-44/rc).

\section{Methods}

\section{Study design}

This retrospective cross-sectional observational study used secondary data and followed the STROBE statement (21). Data from cone-beam computed tomography (CBCT) scans of patients who underwent horizontal ridge augmentation with LBBM blocks were obtained in Digital Imaging and Communication in Medicine (DICOM) format to evaluate the graft volume.

\section{Ethical statement}

The study was conducted following the Declaration of
Helsinki, (as revised in 2013). The study was approved by Research Ethics Committee of the Faculty of Dentistry at UFPEL (No. 011235/2017). Owing to the retrospective design of this study and the use of secondary data, individual consent from patients was waived. However, all patients signed free and informed consent before the surgical procedures.

\section{Sample selection}

Charts of patients who underwent maxillary augmentation procedures before implant placement, between 2010 and 2016, were screened. Adult patients with complete chart data, had undergone grafting procedure using LBBM, did not have previous inflammatory or periapical disease in the grafted area, had no systemic or metabolic conditions that affect bone regeneration, and had available CBCT DICOM data obtained before the reconstruction (T0) and 8 months after reconstruction before the implant placement (T1) were included. Patients who were pregnant at the time of graft surgery or before CBCT, patients with smoking habits, and patients with incomplete data were excluded.

\section{CBCT volume assessment}

After anonymization of data, DICOM datasets from CBCT scans were stored in a hard drive for posterior tridimensional reconstruction in the OsiriX Lite software (Version 8.0.2, Pixmeo, GNU LGPL, Geneva, Switzerland). Reconstructed images were standardized in terms of spatial orientation, the Frankfurt plane was parallel to the ground, the coronal plane crossing the pterygoid plates was perpendicular to the Frankfurt plane, and the sagittal plane was fixed according to the midline crossing the coronal plane in $90^{\circ}$. After head orientation, a new DICOM image with the head in final positions was generated for each patient.

A cross-sectional three-dimensional reconstruction was obtained from the standardized DICOM data. Thus, a single calibrated examiner delimited the corresponding area to the LBBM in the axial plane using the pencil tool in all frames since the first appearance of the graft. Following, the region of interest (ROI) tool was applied to the delimited area, and the "volume ROI" tool was used to calculate the volume of the previously selected area (Figure 1).

\section{Statistical analysis}

Obtained data were pooled according to the demographic 

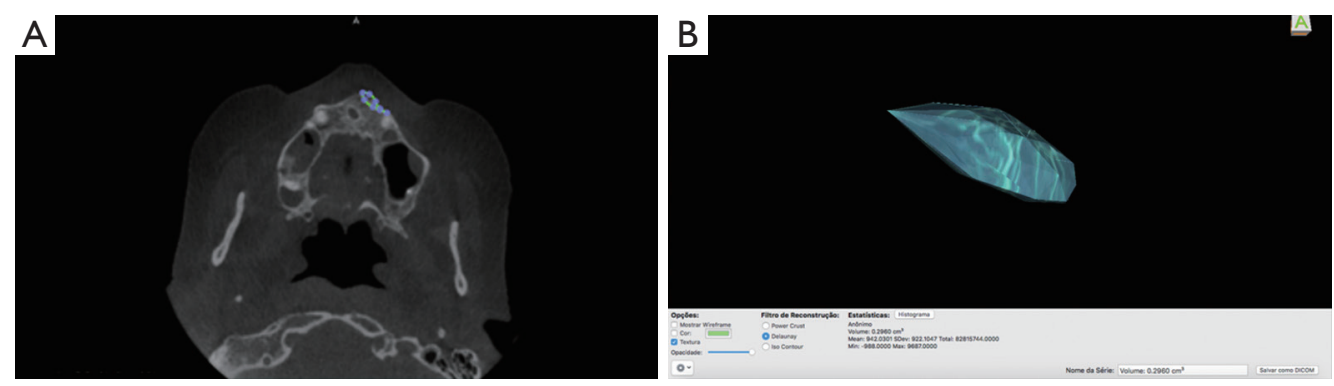

Figure 1 A CBCT eight months post-operative graft image sample. (A) A cone-beam computed tomography scan in the axial view demonstrating the selected ROI in blue. (B) Tridimensional simulated volume according to the selected ROI and ROI volume calculation tool. CBCT, cone-beam computed tomography; ROI, region of interest.

Table 1 Descriptive data of patients submitted do lyophilized bovine bone matrix (LBBM) block graft and CBCT volume of graft prior implant placement

\begin{tabular}{lcccc}
\hline Patient & Age & Gender & Grafted region & LBBM volume $\left(\mathrm{cm}^{3}\right)$ \\
\hline A.X.V & 69 & $\mathrm{~F}$ & Anterior left & 0.253 \\
C.R.V & 48 & $\mathrm{~F}$ & Anterior left & 0.3408 \\
C.R.S & 52 & $\mathrm{~F}$ & Anterior right & 0.3019 \\
C.S.S & 37 & $\mathrm{~F}$ & Anterior left & 0.2960 \\
E.E.O & 51 & $\mathrm{~F}$ & Anterior left & 0.2646 \\
F.R.P & 28 & $\mathrm{~F}$ & Posterior right & 0.2774 \\
G.F.D.A & - & $\mathrm{F}$ & Anterior left & 0.2678 \\
G.F.D.A & - & $\mathrm{F}$ & Anterior right & 0.1292 \\
M.M. & 32 & $\mathrm{~F}$ & Posterior right & 0.1738 \\
M.R.C & 57 & $\mathrm{~F}$ & Anterior right & 0.3975 \\
M.R.C & 57 & $\mathrm{~F}$ & Anterior left & 0.4495 \\
Mean (SD) & $47.89(13.25)$ & & & $0.2839(0.0917)$ \\
\hline
\end{tabular}

characteristics of the patients and augmentation site. Volume measurement data were analyzed using descriptive statistics.

\section{Results}

First, the chart screening identified 34 patients who underwent grafting procedures in the established time interval. Of these patients, only nine met the inclusion criteria, with 11 total sites of bone augmentation. All patients received bone augmentation using OrthoGen ${ }^{\circledR}$ blocks (OrthoGen, Baumer S.A, Mogi MIrim, SP, Brazil), and CT data were obtained at T0. In all cases, T1 CT acquisition before placement of dental implants was performed 8 months after the bone reconstruction.
From all included data, nine augmentation sites were located in the anterior maxilla and two were at the posterior maxilla. Graft failure or graft loss was not observed among those patients. Postoperative complications were not recorded in any of the included cases. All reconstructed areas were rehabilitated with dental implants. The mean volume of the bone graft in the CBCT analysis was $0.2839 \pm 0.0917 \mathrm{~cm}^{3}$ (Table 1).

Demographic data did not show any correlation between the graft volume and sex, age, or surgery site.

\section{Discussion}

Bone augmentation procedures using LBBM are a relatively 
unexplored topic in the current literature. Owing to the complexity and clinical relevance of bone reconstruction, the research of alternative biomaterials is important to facilitate implant clinical practice. According to Hämmerle et al. (13), one of the advantages of bone substitute materials is to prevent the occurrence of the associated morbidity to the second surgical site for donating bone; thus, advances in biomaterials research represent an important advancement in guided bone regeneration techniques.

In a pre-clinical animal study in dogs, Araújo et al. (22) evaluated the on-lay application of LBBM as a scaffold to bone neoformation. These authors concluded that after 6 months of implantation, the LBBM preserves its dimensions, structure, and volume. However, a limited amount of new bone was observed between the graft and the implantation bed, suggesting that a longer healing period may be necessary with the use of LBBM. In the present study, we evaluated the graft material 8 months after implantation and observed a well-incorporated graft, with remaining structure and volume and an acceptable density in the imaging evaluation similar to the host bone. Hämmerle et al. (13) also performed a retrospective analysis in humans and observed in 20 patients that a period of 9-10 months would be the necessary time before implant placement.

The volumetric method for graft evaluation is not often reported in the literature. Most studies have evaluated crestal and apical width, length, and height, with bidimensional measurements. Smolka et al. (23) performed the most similar method. Gorla et al. also used DICOM Works software to assess bone volume, by the sum of areas, following the Cavalieri principle (24).

Our data provide preliminary insights regarding graft incorporation and volume. However, its retrospective design inhibited evaluation of a precise resorption rate, as performed by previous authors $(11,18,20,21)$, which is a limitation of this study. Another limitation was the small sample size, which inhibited further statistical analysis and correlation of bone volume with clinical data.

Block et al. (16) evaluated the width gain of grafted areas with particulate bovine bone matrix, and using CBCT scans, they found a final gain of $1.5 \mathrm{~mm}$. Hämmerle et al. (13) identified a width gain of $3.7 \mathrm{~mm}$ after 6 months. Despite the limitations, it is possible to observe a similar pattern of volume maintenance, as highlighted in the present study, revealing a final volume of $283.9 \mathrm{~mm}^{3}$.

Moreover, Steigmann (19) evaluated LBBM block placement by the frictional method and found a tomographic density similar to the host bone after only 6 months. In the present study, all xenogeneic grafts were placed with passant screw technique, and the healing period was 8 months.

The current knowledge about physiological behavior, osteoconductivity, and success rates of xenografts was obtained most from research about its particulate form, for socket preservation, guided bone regeneration, or sinus lift procedures, as well as for graft volume preservation when associated with autogenous graft. Based on the recent literature, the same features of the particulate bone may be observed in bone blocks $(17,20)$.

\section{Conclusions}

Based on this case series and considering the study limitations, LBBM blocks demonstrated similar tomographic density to the host bone and volume after 8 months of implant placement. Thus, the LBBM block appears to be a valuable alternative to horizontal ridge augmentation.

\section{Acknowledgments}

Funding: None.

\section{Footnote}

Provenance and Peer Review: This article was commissioned by the editorial office, Frontiers of Oral and Maxillofacial Medicine, for the series "Xenogenous and Xeno-synthetic Bone Substitutes: State-of-the-art and Clinical Outcomes". The article has undergone external peer review.

Reporting Checklist: The authors have completed the STROBE reporting checklist. Available at https://fomm. amegroups.com/article/view/10.21037/fomm-21-44/rc

Data Sharing Statement: Available at https://fomm. amegroups.com/article/view/10.21037/fomm-21-44/dss

Conflicts of Interest: All authors have completed the ICMJE uniform disclosure form. (available at https://fomm. amegroups.com/article/view/10.21037/fomm-21-44/ coif). The series "Xenogenous and Xeno-synthetic Bone Substitutes: State-of-the-art and Clinical Outcomes" was commissioned by the editorial office without any funding or sponsorship. PHAC served as the unpaid Guest Editor of the series. The authors have no other conflicts of interest to 
declare.

Ethical Statement: The authors are accountable for all aspects of the work in ensuring that questions related to the accuracy or integrity of any part of the work are appropriately investigated and resolved. The study was conducted in accordance with the Declaration of Helsinki (as revised in 2013). The study was approved by Research Ethics Committee of the Faculty of Dentistry at UFPEL (No. 011235/2017). Owing to the retrospective design of this study and the use of secondary data, individual consent from patients was waived. However, all patients signed free and informed consent before the surgical procedures.

Open Access Statement: This is an Open Access article distributed in accordance with the Creative Commons Attribution-NonCommercial-NoDerivs 4.0 International License (CC BY-NC-ND 4.0), which permits the noncommercial replication and distribution of the article with the strict proviso that no changes or edits are made and the original work is properly cited (including links to both the formal publication through the relevant DOI and the license). See: https://creativecommons.org/licenses/by-nc-nd/4.0/.

\section{References}

1. Fugazzotto PA. Maintenance of soft tissue closure following guided bone regeneration: technical considerations and report of 723 cases. J Periodontol 1999;70:1085-97.

2. Tolstunov L. Surgical Restorative Decision Algorithm for Edentulous Condition in Implant Dentistry With Emphasis on Bone Augmentation. J Oral Implantol 2019;45:421-4.

3. Peleg M, Garg AK, Misch CM, et al. Maxillary sinus and ridge augmentations using a surface-derived autogenous bone graft. J Oral Maxillofac Surg 2004;62:1535-44.

4. Anitua E, Sánchez M, Nurden AT, et al. New insights into and novel applications for platelet-rich fibrin therapies. Trends Biotechnol 2006;24:227-34.

5. Barone A, Aldini NN, Fini $M$, et al. Xenograft versus extraction alone for ridge preservation after tooth removal: a clinical and histomorphometric study. J Periodontol 2008;79:1370-7.

6. Chiapasco M, Zaniboni M, Boisco M. Augmentation procedures for the rehabilitation of deficient edentulous ridges with oral implants. Clin Oral Implants Res 2006;17 Suppl 2:136-59.
7. Jensen SS, Terheyden H. Bone augmentation procedures in localized defects in the alveolar ridge: clinical results with different bone grafts and bone-substitute materials. Int J Oral Maxillofac Implants 2009;24 Suppl:218-36.

8. Kuchler U, von Arx T. Horizontal ridge augmentation in conjunction with or prior to implant placement in the anterior maxilla: a systematic review. Int J Oral Maxillofac Implants 2014;29 Suppl:14-24.

9. Aghaloo TL, Misch C, Lin GH, et al. Bone Augmentation of the Edentulous Maxilla for Implant Placement: A Systematic Review. Int J Oral Maxillofac Implants 2016;31 Suppl:s19-30.

10. Galia CR, Macedo CA, Rosito R, et al. In vitro and in vivo evaluation of lyophilized bovine bone biocompatibility. Clinics (Sao Paulo) 2008;63:801-6.

11. Lima RG, Lima TG, Francischone CE, et al. Bone Volume Dynamics and Implant Placement Torque in Horizontal Bone Defects Reconstructed with Autologous or Xenogeneic Block Bone: A Randomized, Controlled, Split-Mouth, Prospective Clinical Trial. Int J Oral Maxillofac Implants 2018;33:888-94.

12. Zitzmann NU, Schärer $P$, Marinello $\mathrm{CP}$, et al. Alveolar ridge augmentation with Bio-Oss: a histologic study in humans. Int J Periodontics Restorative Dent 2001;21:288-95.

13. Hämmerle CH, Jung RE, Yaman D, et al. Ridge augmentation by applying bioresorbable membranes and deproteinized bovine bone mineral: a report of twelve consecutive cases. Clin Oral Implants Res 2008;19:19-25.

14. de Azambuja Carvalho PH, Dos Santos Trento G, Moura LB, et al. Horizontal ridge augmentation using xenogenous bone graft-systematic review. Oral Maxillofac Surg 2019;23:271-9.

15. Mordenfeld A, Hallman M, Johansson CB, et al. Histological and histomorphometrical analyses of biopsies harvested 11 years after maxillary sinus floor augmentation with deproteinized bovine and autogenous bone. Clin Oral Implants Res 2010;21:961-70.

16. Block MS, Kelley B. Horizontal posterior ridge augmentation: the use of a collagen membrane over a bovine particulate graft: technique note. J Oral Maxillofac Surg 2013;71:1513-9.

17. Dasmah A, Thor A, Ekestubbe A, et al. Particulate vs. block bone grafts: three-dimensional changes in graft volume after reconstruction of the atrophic maxilla, a 2-year radiographic follow-up. J Craniomaxillofac Surg 2012;40:654-9.

18. Block MS, Ducote CW, Mercante DE. Horizontal augmentation of thin maxillary ridge with bovine 
particulate xenograft is stable during 500 days of followup: preliminary results of 12 consecutive patients. J Oral Maxillofac Surg 2012;70:1321-30.

19. Steigmann M. A bovine-bone mineral block for the treatment of severe ridge deficiencies in the anterior region: a clinical case report. Int J Oral Maxillofac Implants 2008;23:123-8.

20. Benic GI, Thoma DS, Jung RE, et al. Guided bone regeneration with particulate vs. block xenogenic bone substitutes: a pilot cone beam computed tomographic investigation. Clin Oral Implants Res 2017;28:e262-70.

21. von Elm E, Altman DG, Egger M, et al. The Strengthening the Reporting of Observational Studies in Epidemiology (STROBE) Statement: guidelines for reporting observational studies. Int J Surg 2014;12:1495-9.

22. Araújo MG, Sonohara M, Hayacibara R, et al. Lateral

doi: $10.21037 /$ fomm-21-44

Cite this article as: Chagas Júnior OL, Kreisner PE, de Azambuja Carvalho PH. A method for cone-beam computed tomography volumetric evaluation of lyophilized bovine bone block for alveolar ridge augmentation: a retrospective study. Front Oral Maxillofac Med 2022;4:2. ridge augmentation by the use of grafts comprised of autologous bone or a biomaterial. An experiment in the dog. J Clin Periodontol 2002;29:1122-31.

23. Smolka W, Eggensperger N, Carollo V, et al. Changes in the volume and density of calvarial split bone grafts after alveolar ridge augmentation. Clin Oral Implants Res 2006;17:149-55.

24. Gorla LF, Spin-Neto R, Boos FB, et al. Use of autogenous bone and beta-tricalcium phosphate in maxillary sinus lifting: a prospective, randomized, volumetric computed tomography study. Int J Oral Maxillofac Surg 2015;44:1486-91.

25. Sbordone L, Toti P, Menchini-Fabris GB, et al. Volume changes of autogenous bone grafts after alveolar ridge augmentation of atrophic maxillae and mandibles. Int J Oral Maxillofac Surg 2009;38:1059-65. 